\title{
Production of $\mathrm{LaCaMnO}_{3}$ Composite by Ball Milling
}

\author{
H. Gencer*, N.E. Cengiz, V.S. Kolat, T. Izgi and S. Atalay \\ Inonu University Science and Arts Faculty, Physics Department, 44069 Malatya, Turkey
}

\begin{abstract}
$\mathrm{La}_{0.67} \mathrm{Ca}_{0.33} \mathrm{MnO}_{3}$ perovskite-type manganite was synthesized by high-energy ball milling raw oxides of $\mathrm{La}_{2} \mathrm{O}_{3}$ (purity $99.9 \%$ ), $\mathrm{CaCO}_{3}$ (purity > 99\%), and $\mathrm{MnO}$ (purity > 99\%). The ratio of ball and powder weight was 10:1 and the rotating speed was set to $500 \mathrm{rpm}$. X-ray analysis indicated that $\mathrm{La}_{0.67} \mathrm{Ca}_{0.33} \mathrm{MnO}_{3}$ single phase was formed completely when milling time is up to $4 \mathrm{~h}$. The peak intensity of perovskite structure decreased and a hump-like peak appeared with further milling time. When the milling time is longer than $40 \mathrm{~h}$, the perovskite structure disappeared and the amorphous phase was formed completely. Scanning electron microscopy picture of $24 \mathrm{~h}$ milled sample showed that the particle size generally varies in a broad range from nanometer scale to a few $\mu \mathrm{m}$. The magnetic measurements showed that ball milling samples have an inhomogeneous magnetic state and exhibit spin-glass like behavior. The significantly small magnetic entropy change and a remarkably broad temperature interval in entropy change were attributed to high degree of structural and magnetic disorder and broadening of magnetic transition.
\end{abstract}

DOI: 10.12693/APhysPolA.125.214

PACS: $81.20 . \mathrm{Ev}, 75.47 . \mathrm{Lx}, 75.30 . \mathrm{Sg}$

\section{Introduction}

In the past few years, the hole doped perovskite manganites with general formula $\mathrm{R}_{1-x} \mathrm{~A}_{x} \mathrm{MnO}_{3}(\mathrm{R}=\mathrm{La}, \mathrm{Pr}$, $\mathrm{Nd} ; \mathrm{A}=\mathrm{Ca}, \mathrm{Sr}, \mathrm{Ba}$ ) have been studied extensively. The interest in these materials is related to their great variety of phenomenology such as colossal magnetoresistance (CMR) [1] and magnetocaloric effect (MCE) [2] and their possible technological applications especially in magnetic recording, magnetic storage and magnetic refrigeration technology [3]. The previous studies have showed that the structural, magnetic and electrical transport properties of manganites are closely related with preparation method and conditions. There are several methods to synthesize lanthanum manganites. The most traditional method is via solid-state reaction of the components [4]. Controlling the temperature during the solid state reaction is one of the major problems. In addition, the solid state reaction method requires high annealing temperature (from 1200 to $1400 \mathrm{~K}$ ) and long sintering time (>10 h) to obtaining homogeneity in the stoichiometry, grain size, porosity and purity. Alternatively, chemical methods such as sol-gel [5] are very sensitive to preparation conditions and complicated chemical process must be manipulated. For both methods, the coast is high with a low yield.

Recently, a new method called as high energy ball milling or mechanical alloying is reported to synthesize perovskite manganites by milling mixture of manganese, alkaline-earth and rare-earth oxides. This process is based on chemical reactions mechanically activated by high-energy ball milling. The previous studies have showed that the high energy ball milling method is a popular technique with advantages including lost-cost,

*corresponding author; e-mail: huseyin.gencer@inonu.edu.tr high yield, low temperature synthesis and versatile way to produce fine particles. Another advantage is that this method could be successfully applied to obtain different oxides.

In this work, we report the synthesis of $\mathrm{La}_{0.67} \mathrm{Ca}_{0.33} \mathrm{MnO}_{3}$ by milling the mixed powders of $\mathrm{La}_{2} \mathrm{O}_{3}, \mathrm{CaCO}_{3}$, and $\mathrm{MnO}$ in a high energy ball mill. The effect of milling time on structural and magnetic properties of samples is investigated in detail.

\section{Experimental}

$\mathrm{LaCaMnO}_{3}$ perovskite-type manganite was synthesized by high-energy ball milling. $\mathrm{La}_{2} \mathrm{O}_{3}$ (purity $99.9 \%$ ), $\mathrm{CaCO}_{3}$ (purity > 99\%), and $\mathrm{MnO}$ (purity > 99\%) powders were used as raw materials. The mixture was milled by conventional planetary ball mill with agate vials and balls. The ratio of ball powder weight was 10:1 and the rotating speed was set to $500 \mathrm{rpm}$. The structural characterization was carried out using X-ray powder diffraction $\left(\mathrm{Cu} K_{\alpha}\right)$. Grain structure was observed using a LEO-EVO-40 scanning electron microscope (SEM). The magnetic measurements were performed using a Q-3398 (cryogenic) magnetometer in a temperature range from 150 to $300 \mathrm{~K}$ and a maximum magnetic field of $6 \mathrm{~T}$ was applied.

\section{Results and discussion}

Figure 1a shows the X-ray diffraction patterns of as milled samples for different milling times up to $56 \mathrm{~h}$. The diffraction peaks belonging to starting oxides $\left(\mathrm{La}_{2} \mathrm{O}_{3}\right.$, $\mathrm{CaCO}_{3}$, and $\mathrm{MnO}$ ) can be clearly seen for $0 \mathrm{~h}$ milled sample. However, the peaks belonging to starting oxides almost disappeared completely after milling for only $2 \mathrm{~h}$. Meanwhile, the new peaks corresponding to perovskite manganite structure begin to appear for $2 \mathrm{~h}$ milled sample as can be seen from peak located at $2 \theta=32^{\circ}$. The X-ray diffraction peaks have shown that the $\mathrm{La}_{0.67} \mathrm{Ca}_{0.33} \mathrm{MnO}_{3}$ single phase is formed completely when the milling time is up to $4 \mathrm{~h}$. 


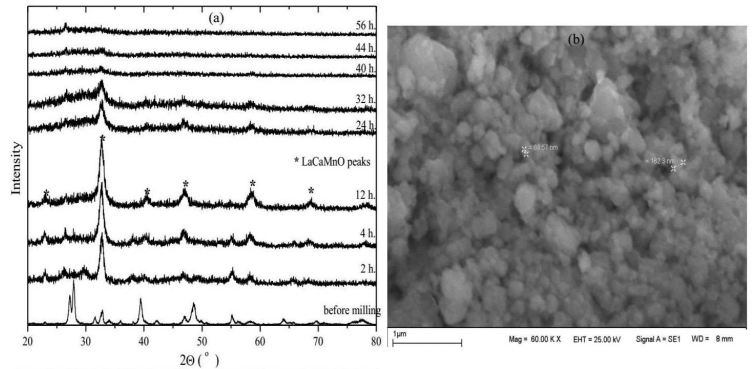

Fig. 1. (a) XRD patterns of $\mathrm{La}_{0.67} \mathrm{Ca}_{0.33} \mathrm{MnO}_{3}$ samples milled for various times. (b) SEM picture of $\mathrm{La}_{0.67} \mathrm{Ca}_{0.33} \mathrm{MnO}_{3}$ sample milled for $24 \mathrm{~h}$.

For the further milling time up to $12 \mathrm{~h}$, the increase in peaks intensities belonging to perovskite structure shows that the amount of the crystalline phase is increased with increasing milling time.

For the samples milled longer than $12 \mathrm{~h}$, the intensity of peaks belonging to perovskite structure began to decrease gradually and a hump-like peak appeared with further milling time. The decrease in intensity of peaks has shown that an amorphous phase begins to build up when the milling time is longer than $12 \mathrm{~h}$.

As can be seen from Fig. 1a, when the milling time is longer than $40 \mathrm{~h}$, the perovskite structure disappears and the amorphous phase is formed completely. The results indicated that by adjusting the milling time the perovskite phase can be transformed into the amorphous phase. However, X-ray analyses have shown when the milling time reached above $56 \mathrm{~h}$, the crystallization peaks (which were not given here) began to appear again. The synthesis of $\mathrm{La}_{0.67} \mathrm{Ca}_{0.33} \mathrm{MnO}_{3}$ single phase simply by milling raw materials has shown that the high energy ball milling is an another useful method to produce the stoichiometric and homogeneous manganite perovskites in addition to the conventional solid-state reaction method. Another advantage is that by adjusting the milling time the sample could be transformed from crystalline perovskite phase to amorphous phase.

In order to obtain further information about grain morphology, $\mathrm{La}_{0.67} \mathrm{Ca}_{0.33} \mathrm{MnO}_{3}$ was examined by SEM. Figure 1b shows typical SEM micrograph for $24 \mathrm{~h}$ milled raw $\mathrm{La}_{0.67} \mathrm{Ca}_{0.33} \mathrm{MnO}_{3}$ sample. Although, the particle size generally varies in a broad range from $\mathrm{nm}$ scale to a few $\mu \mathrm{m}$, the samples that have been subjected to milling consist mainly of small particle of nanometers order and the most of these small grains have nearly spherical shape. The SEM images of all samples (which were not given here) showed that the average particle size first decreased with increasing milling time up to $6 \mathrm{~h}$ and then a small increase was observed in particle size with further increasing milling time.

Figure $2 \mathrm{a}$ shows the temperature dependence of the magnetization for $\mathrm{La}_{0.67} \mathrm{Ca}_{0.33} \mathrm{MnO}_{3}$ samples milled at different times. The data were taken under an applied field of $0.1 \mathrm{~T}$ after the samples were zero field cooled (ZFC) and field cooled (FC). It is clearly seen that the magnetization increases gradually over a broad range as the temperature decreases. The broad and continuous magnetic transition probably indicates that an inhomogeneous magnetic state prevails in the transition region. At low temperatures, the magnetization shows a splitting between the $\mathrm{ZFC}$ and $\mathrm{FC}$ curves. In many studies, it has been concluded that a clear difference in ZFC and FC magnetization curves is undoubtedly not of a typical full ferromagnetic but of an inhomogeneous magnetic state [6]. It is generally known that the discrepancy between the ZFC and FC curves is usually ascribed to the appearance of spin-glass like behavior induced by competition between the ferromagnetic and antiferromagnetic exchange interaction [7].

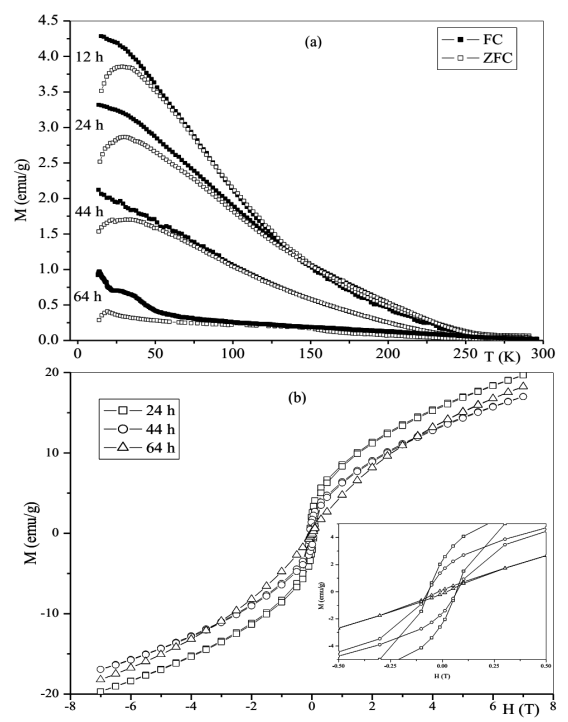

Fig. 2. (a) The temperature dependence of the magnetization of $\mathrm{La}_{0.67} \mathrm{Ca}_{0.33} \mathrm{MnO}_{3}$ samples milled at different times. (b) Isothermal magnetization curve measured at $5 \mathrm{~K}$ for $\mathrm{La}_{0.67} \mathrm{Ca}_{0.33} \mathrm{MnO}_{3}$ samples milled at different times. The inset shows the enlarged version of $M-H$.

Figure $2 \mathrm{~b}$ shows the magnetization measurement as a function of magnetic field for $\mathrm{La}_{0.67} \mathrm{Ca}_{0.33} \mathrm{MnO}_{3}$ samples milled at different times at a temperature of $5 \mathrm{~K}$. It is clearly seen that all the magnetization curves do not show saturation in a field of up to $7 \mathrm{~T}$ magnetic field. The deviation of magnetization curves from the linear relation indicates that this magnetic behavior could not be simply interpreted as paramagnetic behavior. As can be seen in the inset in Fig. 2b, the isothermal magnetization curves display a very small hysteresis and the very low coercive fields at $5 \mathrm{~K}$ which confirms the very soft ferromagnetic behavior of the samples consisting of basically antiferromagnetic with a weak ferromagnetism as in the case of spin-glass systems. However, the maximum magnetization values observed at $7 \mathrm{~T}$ magnetic field and at $5 \mathrm{~K}$ are significantly lower than that of same $\mathrm{La}_{0.67} \mathrm{Ca}_{0.33} \mathrm{MnO}_{3}$ samples prepared by other conventional methods $[4,5]$.

In mixed valence perovskite manganites, net magnetization mainly comes from the magnetic moments of $\mathrm{Mn}^{3+}$ and $\mathrm{Mn}^{4+}$ ions. In ball milled samples, due to 
the low crystalline quality $\mathrm{Mn}^{3+}$ and $\mathrm{Mn}^{4+}$ ions distribution could be random. In this case, some Mn separation will be less than others and hence the predicted ferromagnetism may occur only locally which indicates the presence of magnetic disorder results in a decrease in the net magnetization [6, 7]. In our previous study, the similar magnetic behaviors were observed in the same $\mathrm{La}_{0.67} \mathrm{Ca}_{0.33} \mathrm{MnO}_{3}$ sample prepared by sol-gel method which has also nanostructure [5]. It is clear that the nanoscale crystal often exhibits magnetic properties that are different from those of their bulk counterparts [8].

The magnetic entropy, which is associated with the MC effect, can be calculated from the isothermal magnetization curves (Fig. 3a) under the influence of a magnetic field. According to the classical thermodynamical theory, the magnetic entropy change $\Delta S_{\mathrm{m}}$ produced by the variation of a magnetic field from 0 to $H_{\max }$ is given by

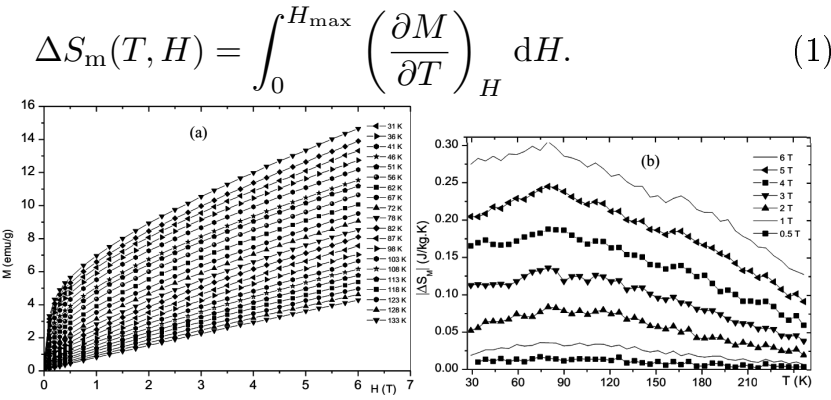

Fig. 3. (a) Isothermal magnetization curves at various temperatures. (b) Magnetic entropy change at various magnetic fields for $12 \mathrm{~h}$ milled $\mathrm{La}_{0.67} \mathrm{Ca}_{0.33} \mathrm{MnO}_{3}$ sample.

To evaluate the magnetic entropy change $\Delta S_{\mathrm{m}}$, a numerical approximation of the integral in Eq. (1) and the experimental $M-H$ curves at various temperatures have been used. Figure $3 \mathrm{~b}$ shows the magnetic entropy change as a function of temperature at various magnetic fields for $12 \mathrm{~h}$ milled $\mathrm{La}_{0.67} \mathrm{Ca}_{0.33} \mathrm{MnO}_{3}$ sample. It is clearly seen that the magnetocaloric effect occurs in a considerably large temperature interval. On the other hand, a significant decrease in the value of $\Delta S_{\mathrm{m}}$ was observed. The maximum entropy change for $12 \mathrm{~h}$ milled sample is only $0.3 \mathrm{~J} /(\mathrm{kg} \mathrm{K})$ at $6 \mathrm{~T}$ magnetic field which is very much smaller than that of the same polycrystalline $\mathrm{La}_{0.67} \mathrm{Ca}_{0.33} \mathrm{MnO}_{3}$ samples prepared by other conventional methods $[4,5]$. A reduction in value of $\Delta S_{\mathrm{m}}$ accompanied by a broadening of $\Delta S_{\mathrm{m}}$ peak is a characteristic feature observed for manganites when particle size decreased $[9,10]$. In previous studies, it has been concluded that such an evolution in magnetocaloric effect for nanoscale manganites could be due to high degree of structural and magnetic disorder and broadening of magnetic transition $[9,10]$. While the magnetic entropy change in ball milled manganites is significantly small, the magnetic entropy change of these samples is spread over a remarkably broad temperature interval which makes these samples potentially considered as interesting refrigerants below room temperature.

\section{Conclusions}

In this study, magnetic $\mathrm{La}_{0.67} \mathrm{Ca}_{0.33} \mathrm{MnO}_{3}$ perovskite-type manganite was synthesized by high-energy ball milling raw oxides of $\mathrm{La}_{2} \mathrm{O}_{3}$ (purity 99.9\%), $\mathrm{CaCO}_{3}$ (purity > 99\%), and $\mathrm{MnO}$ (purity > 99\%). The ratio of ball and powder weight was 10:1 and the rotating speed was set to $500 \mathrm{rpm}$. X-ray analysis indicated that $\mathrm{La}_{0.67} \mathrm{Ca}_{0.33} \mathrm{MnO}_{3}$ single phase was formed completely when milling time is up to $4 \mathrm{~h}$. The peak intensity of perovskite structure decreased and a hump-like peak appeared with further milling time. When the milling time is longer than $40 \mathrm{~h}$, the perovskite structure disappeared and the amorphous phase was formed completely.

SEM picture of $24 \mathrm{~h}$ milled sample showed that the particle size generally varies in a broad range from nm scale to a few $\mu \mathrm{m}$. The SEM images of all samples showed that the average particle size first decreased with increasing milling time up to $24 \mathrm{~h}$ and then a small increase was observed in particle size with further increasing milling time.

The broadening of magnetic transition, the splitting between the $\mathrm{ZFC}$ and $\mathrm{FC}$ magnetization curves, a very small hysteresis, and the very low coercive fields have shown that the samples have an inhomogeneous magnetic state and exhibit spin-glass like behavior. The magnetic entropy change in ball milled manganites is significantly small. However, the magnetic entropy change of the sample is spread over a remarkably broad temperature interval. The maximum entropy change for $12 \mathrm{~h}$ milled sample was only $0.3 \mathrm{~J} /(\mathrm{kg} \mathrm{K})$ at $6 \mathrm{~T}$ magnetic field.

\section{Acknowledgments}

This work was supported by Inonu University Research Fund with the project number 2012/169.

\section{References}

[1] V.K. Pecharsky, K.A. Gschneidner, A.O. Tsokol, Rep. Prog. Phys. 68, 1479 (2005).

[2] M.H. Phan, S.C. Yu, J. Magn. Magn. Mater. 308, 325 (2007).

[3] M. Fiebig, J. Phys. D, Appl. Phys. 38, R123 (2005).

[4] V.S. Kolat, H. Gencer, M. Gunes, S. Atalay, Mater. Sci. Eng. B 140, 212 (2007).

[5] H.I. Adiguzel, V.S. Kolat, H. Gencer, T. Seckin, S. Atalay, Int. J. Mod. Phys. B 21, 43 (2007).

[6] Z.M. Stanojevic, Z. Brankovic, Z. Jaglicic, M. Jagodic, L. Mancic, S. Bernik, A. Recnik, G. Brankovic, J. Nanopart. Res. 13, 3431 (2011).

[7] M.P. Nešic, Z.M. Stanojevic, Z. Brankovic, P. Cotic, S. Bernik, M.S. Goes, A. Marinkovic, J.A. Varela, G. Brankovic, J. Alloys Comp. 552, 451 (2013).

[8] M. Muroi, R. Street, P.G. McCormick, J. Appl. Phys. 87, 3424 (1999).

[9] S. Xi, W. Lu, Y. Sun, J. Appl. Phys. 111, 063922 (2012).

[10] M. Pekala, V. Drozd, J.F. Fagnard, P. Vanderbemden, M. Ausloos, Appl. Phys. A 90, 237 (2008). 